\title{
Locomotive Lifter for Parking in Congested Places
}

\author{
Tamilvanan.A, Sampath Kumar.K, Sanjaya Krishnan.K.B, Saravana Kumar.D
}

\begin{abstract}
Locomotive Lifter is an independent attachment implied on the vehicle body frame in order to lift and move the vehicle at right angles from it's exact position using the retractable arm provided with the wheel dolly for parking in congested places. It works on the principle that the fluid pressure (hydraulic or pneumatic) applied in the piston cylinder respectively pulls the arm and lifts the vehicle, due to small area of the wheel dolly the effort (force applied) to push the vehicle is less irrespective of the immense structure of the vehicle. Now-adays the most common issue probably dealt in metropolitan cities is that the mishap in parking the car in the portico or on the adjacent road side parallelly with part of the car body to be hanging outside the passage. Merely, there is enough of space to park the car but to say it is hardly occupied. The unoccupied space is due to irregular parking of the other cars crossing the parking lanes on the either sides in parallel parking or the standing pillar in indoor parking which does not allow the car to turn with it's free radius of curvature. In order to park the car perfectly one has to arrest the position of the either axial of the car and the other axial wheel has to be tilt at right angles to make an arc to park. But this case isn't possible i.e. tilting the wheels at right angle. Besides the help of this "Locomotive Lifter" we can rotate the position of the car in all 360'degree direction, either the car can be moved or the car can be rotated.
\end{abstract}

Keywords: Merely, there is enough of space to park the car but to say it is hardly occupied.

\section{INTRODUCTION}

The retractable arm powered by pressurized fluid piston is pivotally supported from the center of the fabricated bar frame on the either axle of the vehicle body. Each jack assembly is provided with two retractable arms coupled with the fluid piston cylinder. Here the reciprocating motion of the piston respectively moves the arm along the pivot axis for horizontal levelling of the vehicle. This invention relates to horizontal levelling of the vehicle by elevating the vehicle body frame from engaging the wheel dolly to the ground surface, thus providing the ease for moving the vehicle body in desired direction for parking.The jack assembly of this invention is applicable to general vehicular use where it is desired to elevate the vehicle frame relative to the vehicle ground engaging wheels. However, it is particularly adaptable to four wheeled mobile home vehicles whether of the self-propelled or towed type.

Revised Manuscript Received on December 30, 2019.

* Correspondence Author

Mr.Tamilvanan.A, Assistant Professor, Department of Mechanical Engineering, Kongu Engineering College, Perundurai, Erode.

Mr.Sampath Kumar.K, Final Year (Undergraduate course),Department of Mechanical Engineering, Kongu Engineering College, Perundurai, Erode.

Mr.Sanjaya Krishanan.K.B, Final Year (Undergraduate course), Department of Mechanical Engineering, Kongu Engineering College, Perundurai, Erode.

Mr.Saravana Kumar.D, Final Year (Undergraduate course),Department of Mechanical Engineering, Kongu Engineering College, Perundurai, Erode.

(C) The Authors. Published by Blue Eyes Intelligence Engineering and Sciences Publication (BEIESP). This is an open access article under the CC BY-NC-ND license (http://creativecommons.org/licenses/by-nc-nd/4.0/)

\section{OBJECTIVES OF INVENTION}

$>$ To fabricate a retrieving arm lifter to lift the vehicle which is an independent attachment.

$>$ To facilitate the car to rotate or move with little force in case of parking at the narrow places.

$>$ To facilitate the vehicle to lift even in the case of wheel replacement for puncture.

$>$ To imply programmed automation to reduce the manual risk (an existing lifter) in lifting the vehicle.

\section{PROPOSED METHODOLOGY}

This independent attachment is fixed on the vehicle frame near the front and back axle under the chassis of the vehicle. The pressurized fluid circuit extends and retracts accordingly to drop and lift the arm which acts on basis of lever mechanism reflects the vehicle position from horizontal levelling. Once the vehicle is lifted a safety lock is engaged so that the arm never retracts back. A familiar know law that the force is equally divided per area provided. The wheel fixture has small wheels which facilitate to move the car with little effort. Once the work is done the fluid piston cylinder retracts the arm and the vehicle is placed on the ground surface. The accompanied flow process is shown in Fig.1.

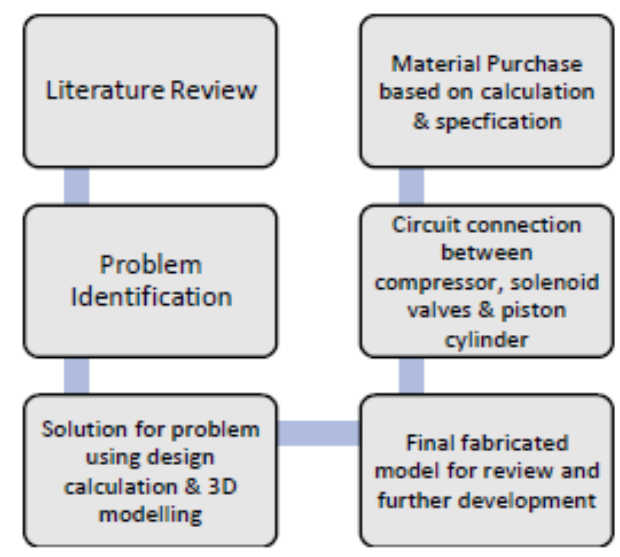

Fig.1 Flow process of proposed methodology

\section{PROBLEM DEFINITION}

Merely, there is enough of space to park the car but to say it is hardly occupied. The unoccupied space is due to irregular parking of the other cars crossing the parking lanes on the either side in parallel parking or the standing pillar in indoor parking which does not allow the car to turn with it's free radius of curvature. In order to park the car perfectly one has to arrest the position of the either axial of the car and the other axial wheel has to be tilt at right angles to make an arc to park. But this case isn't possible i.e. tilting the wheels at right angle. 


\section{Locomotive Lifter for Parking in Congested Places}

Besides the help of this "Locomotive Lifter" we can rotate the position of the car in all 360'degree direction, either the car can be moved or the car can be rotated.

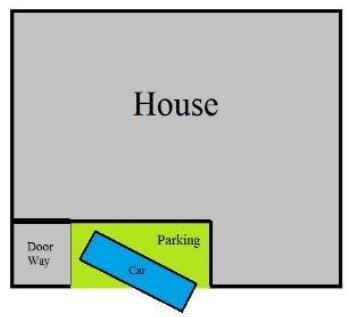

(a) Dissimilarity in Parking

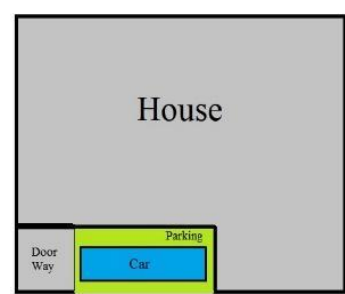

(b) Perfect Parking
Fig.2. Variation of imperfect \& perfect parking

Case (a): This is the regular mishap in parking the car in congested places. Due to its radius of curvature over a turn the car takes a wider path at its outer side whereas a short turn at its inner side. Thus, the car moves forward along with a turn so there lay the dissimilarity in parking the car with respect to its parking lot in the congested places which is shown in the Fig.2.

Case (b): With the help of this Locomotive Lifter one can alter the position of the car. In simple, he can just drag the car sideways with little effort. Because the wheel fixture provides the ease in moving the car easily accordingly to the principle that the smaller the area slighter the force to be applied which is shown in the Fig.2.

\section{DESIGN}

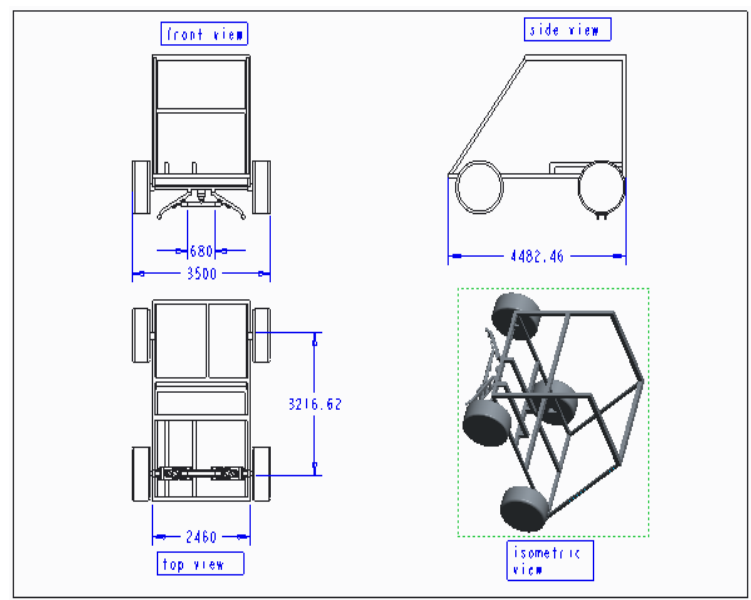

Fig.3.CAD modelling

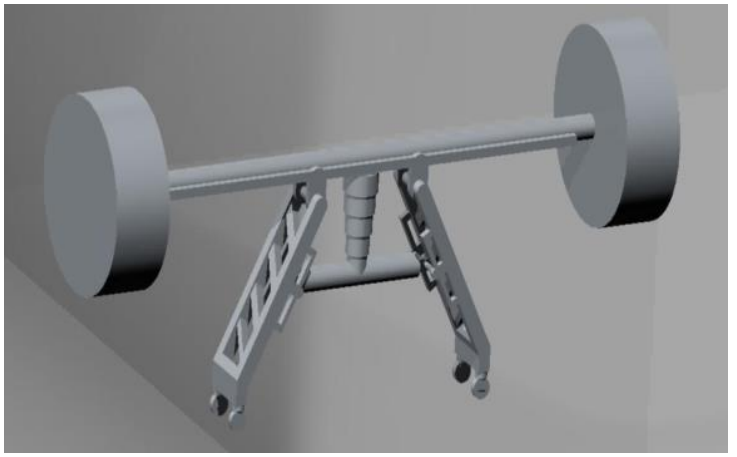

Fig.4.Isometric view

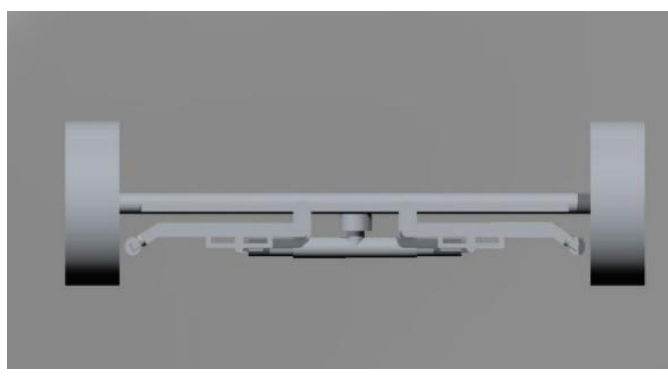

Fig.5.Cylinder at initial position

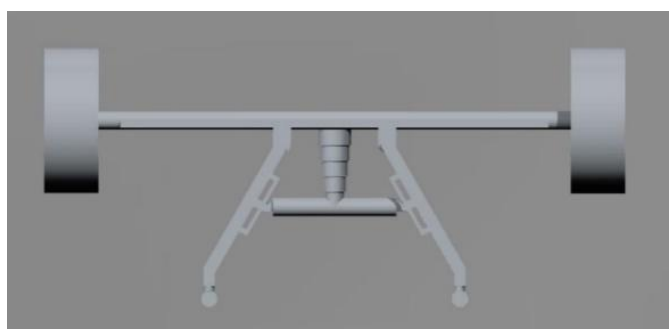

Fig.6.Cylinder at final position

The front view, side view, top view and isometric view of the attachment fixed in the fabricated car model is designed using CAD modelling software is shown in Fig.3. The isometric view of the unfixed individual component is shown in Fig.4. The operating positions of the cylinder during initial and final conditions are shown in Fig.5 and Fig.6 respectively.

\section{DESIGN CALCULATION}

Given :

$\operatorname{Mass}(m)=80 \mathrm{~kg}$

$\operatorname{Gravity}(g)=9.81 \mathrm{~N}$

Angle $(\theta)=30^{\circ}$

Length $(l)=60 \mathrm{~mm}$

$\operatorname{Breadth}(b)=60 \mathrm{~mm}$

We know that,

$$
F=m g=80 \times 9.81=784.8 N
$$

Resolving forces,

$$
\begin{gathered}
F(x)=F \times \cos \theta=784.8 \times \cos (30)=679.65 N \\
F(y)=F \times \sin \theta=784.8 \times \sin (30)=392.4 N
\end{gathered}
$$

Therefore the uplift force is taken as,

$$
F(y)=392.4 N
$$

The sustainable pressure required to balance the weight along the horizontal axis is calculated from $\mathrm{F}(\mathrm{x})$ as follows,

$$
P=\frac{F}{A}
$$


Here,

$\mathrm{P}$ - Pressure

$\mathrm{F}$ - Force

A - Area

Cross-sectional Area,

$$
A=l \times b=60 \times 60=3600 \mathrm{~mm}^{2}
$$

Now calculating pressure required,

$$
P=\frac{679.65}{3600}=0.1887 \mathrm{~N} / \mathrm{mm}^{2}
$$

We know that,

$$
\begin{gathered}
1 P s i=6894.76 \mathrm{~N} / \mathrm{m}^{2} \\
P=0.1887 \mathrm{~N} / \mathrm{mm}^{2}=27.36 P s i \\
P \simeq 28 P s i
\end{gathered}
$$

Availability:

Provided portable Air Compressor of the capacity of 100 Psi. Thus the design is safe and sufficient to lift.

\section{EXPERIMENTAL RESULTS}

The maximum pressure required to lift the vehicle above the ground surface is 28Psi. As the degrees of the angle of the arm increases the vehicle lifting is at it's maximum, the sustainable pressure required to withstand the load is also minimum as calculated and shown in Table-I.

\begin{tabular}{|c|c|c|c|}
\hline $\begin{array}{c}\text { Angle } \\
\text { (in degrees) }\end{array}$ & $\begin{array}{c}\text { Horizontal } \\
\text { force F(x) } \\
\text { (N) }\end{array}$ & $\begin{array}{c}\text { Vertical } \\
\text { force F(y) } \\
(\mathrm{N})\end{array}$ & $\begin{array}{c}\text { Pressure } \\
\text { Required } \\
\text { (Psi) }\end{array}$ \\
\hline 30 & 679.65 & 392.4 & 28 \\
\hline 45 & 554.9 & 554.9 & 22 \\
\hline 60 & 392.4 & 679.65 & 16 \\
\hline
\end{tabular}

Table-I. Variation in pressure

\section{SELECTION OF MATERIAL AND PROCESS}

\section{A. Selection}

1. Mild steel material is used for frames and arms.

2. Mild steel material is resistive to breakage, high tensile and impact strength.

3. Aluminium alloy rims is used as wheel dolly.

4. Is the most effective material used for withstanding the weight of the car.

\section{B. Process}

1. The mountings of engine, steering and seating is mounted above the main frame.

2. The independent arm with wheel dolly is mounted below the main frame.

3. The operative mechanism is attached to the combination of connections.

\section{WORKING PROCEDURE}

$>$ This independent attachment is pivotally supported on bar frame fixed near the front and back axle under the chassis of the vehicle.
$>$ The fluid circuit extends and retracts accordingly to drop and lift the lever which acts as the arm which reflects the vehicle position.

$>$ Once the vehicle is lifted a safety lock is engaged so that the lever never retracts back.

$>$ A familiar know law that the force is equally divided per area provided. The wheel fixture has small wheels which facilitate to movement of the vehicle with little effort.

$>$ Once the work is done the fluid piston cylinder retracts the arm.

\section{CONCLUSION}

In conclusion, the wheel dolly's constructional advantages are multiple. This type of device is more economical and is well suitable for vehicles that are to be parked in very congested areas at the economical cost. This project can lift the vehicle, that is use to push and park the vehicle manually and this lifting purpose can also be used for changing wheels, that is this lifter is used as the jack for replacement of flat tyres. This device is economically viable, can be used by any kind of person. It does not require more time for the operation. From this innovative project the mishap in parking in congested places is confidently dealt in the hard space for parking and replacement of flat tyre by this lifting mechanism is intensified.

\section{REFERENCES}

1. Earl R Carruthers, Dual wheel and Tire lift, 1945-2019, US2380415A ${ }^{[1]}$.

2. Hector Ray Hernandez, Automobile jack and wheel dolly, 20092027, US7597524B2 ${ }^{[2]}$.

3. Robert Casey, Dolly for towing wheels, 1987-2019, US4696484A ${ }^{[3]}$

4. Robert O Ray, Wheel dolly, 1946-2019, US2392409A ${ }^{[4]}$.

5. Charles W Frame \& Jack A Rickrode, Hydraulic bearing mounting press, 1975-2019, US3916499A ${ }^{[5]}$.

\section{AUTHORS PROFILE}

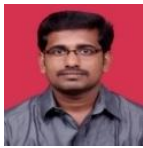

Mr.Tamilvanan.A,Assistant Professor, Department of Mechanical Engineering, Kongu Engineering College, Perundurai, Erode.

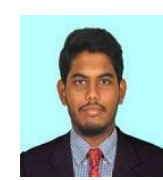

Mr.Sampath Kumar.K, Final Year (Undergraduate course),Department of Mechanical Engineering, Kongu Engineering College, Perundurai, Erode.

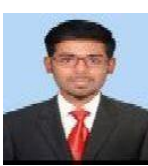

Mr.Sanjaya Krishanan.K.B, Final Year (Undergraduate course), Department of Mechanical Engineering, Kongu Engineering College, Perundurai, Erode.

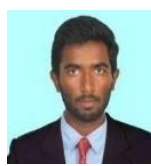

Mr.Saravana Kumar.D, Final Year (Undergraduate course),Department of Mechanical Engineering, Kongu Engineering College, Perundurai, Erode. 